prophylaxis in patients subjected to appendicectomy is surprising on the evidence presented. The possibility of rendering a valuable drug useless by the emergence of resistance is not discussed and methods effective against both aerobes and anaerobes are not mentioned. For example, Gilmore and Martin $^{1}$ and Gilmore and Sanderson ${ }^{2}$ showed excellent results with providone-iodine in careful studies on much larger numbers of patients and took into account many extraneous factors not considered in this metronidazole trial.

It is very doubtful if seven days' prophylaxis as practised by $\mathrm{Dr}$ Willis and his colleagues is necessary. Two doses only of tobramycin or gentamicin plus lincomycin, timed to cover the operative and immediate postoperative period, was shown to be effective in reducing wound infection. ${ }^{3}$ This regimen, or povidone-iodine, deals with aerobic as well as anaerobic infection, whereas metronidazole is useless against aerobes. Until recently the importance of nonclostridial anaerobic infection has been underestimated. The ease with which these organisms can now be isolated and infection by them treated should not lead us to overemphasise their importance.

Possibly metronidazole will prove to be unique and anaerobes will remain sensitive to it, but at present wholesale prolonged prophylaxis with it seems unwise.

Microbiology Department, University College Hospital, London WC1

Gilmore, O J A, and Martin, T D M, British fournal

' Gilmore, O J A, and Sanderson, P J, British fournal of Surgery, 1975, 62,792.

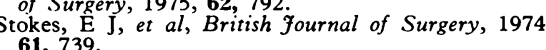

SIR,-Dr A $T$ Willis and his colleagues (7 February, $p$ 318) have shown the value of metronidazole in preventing bacteroides infection after appendicectomy in their study of 95 patients. Their claim that it is improper to withhold it from patients subjected to this common procedure is, however, open to question. It is perturbing to note that aerobic wound infections were over twice as common in the metronidazole group (5) as in the control group (2), even if they were not as severe. Surely prophylaxis against postoperative infection should be aimed at both aerobes and anaerobes, the latter possibly being more important in the gangrenous or perforated cases.

In Reading a controlled trial of 450 patients subjected to grid-iron appendicectomy was undertaken. ${ }^{1}$ Swabs were taken from the outer appendix wall before its removal and from the wound prior to closure. Bacteroides spp were isolated from the appendix wall in nine cases and from the wound in eight, whereas Escherichia coli was isolated from 90 and 61 patients respectively. After swabs had been taken the patients were randomly allocated to one or other of three treatment groups. The wounds of the 151 patients in the first group formed untreated controls. The wounds of the 150 patients in the second group were sprayed with a polyantibiotic spray (Dispray) containing neomycin, bacitracin, and polymixin and those of the 149 in the third group were sprayed with dry powder povidoneiodine (Disadine DP). Postoperative wound infections developed in 24 patients in the control group (three due to Bacteroides $\mathrm{sp}$ ) compared with 14 in the polyantibiotic group (two due to Bacteroides sp) and 12 in the povidone-iodine group (none due to Bacteroides sp). All but one of the bacteroides infections occurred in patients with a gangrenous or perforated appendix. Povidone-iodine halved the overall infection rate $(P<0.025)$, reducing infection from aerobes as well as anaerobes in all degrees of inflammation.

The efficacy of povidone-iodine has since been confirmed in a study of 144 consecutive patients undergoing various abdominal operations at the North Middlesex Hospital, London. ${ }^{2}$ Once more the nature of the infecting organisms was carefully considered; only three of the 24 wound infections in this study were due to Bacteroides spp. Povidoneiodine, which, like elemental iodine, is equally active against different bacterial species, ${ }^{3}$ again significantly reduced the overall incidence of infection $(P<0.01)$, being most effective in wounds with the heaviest bacterial contamination. Although interparietal povidone-iodine will not preven intraperitoneal sepsis it reduces wound infection, the commonest complication in surgery. Furthermore, one spray with an aerosol in theatre is cheaper and considerably less of a burden on the nursing staff than the eight-hourly administration of suppositories (or tablets) for one week.

There appears to be a place for a controlled trial comparing metronidazole with dry powder povidone-iodine or one to assess their efficacy in combination. I certainly do not think the time has come when it would be improper to do an appendicectomy without metronidazole cover.

\section{St Bartholomew's Hospital}

O J A GiLMORE BC

' Gilmore, O J A, and Martin, T D M, British fournal of Surgery, 1974, 61, 28 ${ }^{2}$ Gilmore, $\mathrm{O} \mathrm{J}$ A, and Sanderson, P J, British fournal Sykes, G, Disinfection and Sterilisation, 2nd edn,
p 401. London, Chapman and Hall, 1965 .

\section{Preventing animal disease}

SIR,-Your leading article (14 February, p 355) raises some important points regarding collaboration between the medical and veterinary professions. Both professions have been working together for very many years in the field of meat hygiene, and this collaboration was further developed 10 years ago in the early days of Sir James Howie's directorship of the Public Health Laboratory Service when the PHLS and the Animal Health Division of the Ministry of Agriculture, Fisheries and Food formed a committee to look into mutual problems. This committee has now changed its format by including members of the DHSS ; it is now called the Zoonoses Working Group and its minutes are circulated to interested medical and veterinary bodies in the UK. Encouragement for the group has come from three parent bodies, the directorate of the PHLS, the Animal Health Division, and the DHSS. One of the authors of this letter was an original committee member and has seen the development of this excellent medicoveterinary co-operation and it is not unrealistic to believe that some important zoonoses control measures stemmed from this committee.

The Zoonoses Order of 1975 was described in the Veterinary Record of 12 July 1975. It was the first piece of legislation of its kind, bridging the gap between the veterinary and medical fields, and gave powers to control salmonella infections in certain animals which were a serious threat to human health. Quite as important, it made salmonella infections in animals reportable and allowed investigation of outbreaks. The objective was therefore to build up epidemiological knowledge so that sources of infection and means of spread could be identified and influenced, at least by advice. To facilitate the operation of this Order and discuss problems of mutual interest local zoonoses groups with medical, veterinary, and environmental health representation have been set up throughout the country during the past six months. The task is big and needs the co-operation, among others, of farmers, veterinary surgeons, manufacturers, and processors, as well as the professions.

The recycling of infection between animals by means of animal wastes incorporated in the diet is acknowledged and steps are being taken to control this means of spread. The Diseases of Animals (Waste Foods) Order of 1973 has resulted in very high standards in swill-processing plants. A companion order presently under consideration should very substantially raise the hygienic standards of animal protein fed to animals.

Water is a not unimportant source of salmonella infections to animals and it is interesting to conjecture how often that source of contamination is man. Here again there is collaboration and a group including the PHLS, the Veterinary Investigation Service, and water authorities are surveying and studying the problem.

This is by no means the complete catalogue of activities against the zoonoses, but sufficient perhaps to indicate that you were ill-informed about the great amount of work and effort that has been put into control measures for salmonellosis in particular, in both the medical and the veterinary field. Anyone who has been involved in this work over the past 10 years cannot but be gratified with the close cooperation that now exists between the two professions. We see no need to "knock the heads of two responsible Government departments together." They are already getting on with the job.

D J H PAYNE

Public Health Laboratory,

St Mary's General

Ministry of Agriculture, Fisheries, and Food,

E. LOWES

Tolworth,

Surbiton, Surrey

SIR,-Your leading article (14 February, $p$ 355 ) on this subject is welcome, particularly in relation to salmonellosis and food poisoning, which are now the commonest notifiable diseases after measles. The number of cases of food poisoning investigated in the London Borough of Waltham Forest in 1975 was 260,

Food poisoning, London Borough of Waltham Forest

\begin{tabular}{|c|c|c|c|}
\hline Organism & $\begin{array}{c}\text { General } \\
\text { outbreaks }\end{array}$ & $\begin{array}{c}\text { Family } \\
\text { outbreaks } \\
\text { and } \\
\text { sporadic } \\
\text { cases }\end{array}$ & Tota \\
\hline 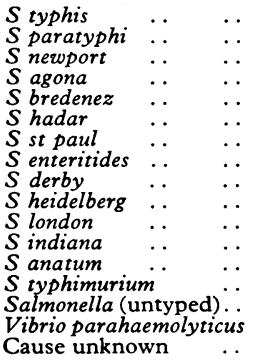 & $\begin{array}{r}139 \\
7^{*}\end{array}$ & $\begin{array}{r}1 \\
2 \\
8 \\
1 \\
3 \\
2 \\
1 \\
1 \\
24 \\
2 \\
1 \\
31\end{array}$ & $\begin{array}{r}1 \\
1 \\
143 \\
6 \\
7 \\
1 \\
2 \\
8 \\
1 \\
3 \\
2 \\
1 \\
1 \\
24 \\
2 \\
1 \\
56\end{array}$ \\
\hline & 171 & 89 & 260 \\
\hline
\end{tabular}

* Same outbreak.

Population: 228200 persons. Rate/100 000 population/ annum: 113 cases. 